\title{
A Atenção Básica à Saúde e a construção das redes temáticas de saúde: qual pode ser $\mathrm{o}$ seu papel?
}

\author{
Primary healthcare and the construction of thematic health \\ networks: what role can they play?
}

Luiz Carlos de Oliveira Cecilio ${ }^{1}$

Rosemarie Andreazza ${ }^{1}$

Graça Carapinheiro ${ }^{2}$

Eliane Cardoso Araújo ${ }^{1}$

Lissandra Andion de Oliveira ${ }^{1}$

Maria da Graça Garcia Andrade ${ }^{3}$

Consuelo Sampaio Meneses ${ }^{1}$

Nicanor Rodrigues da Silva Pinto ${ }^{1}$

Denizi Oliveira Reis ${ }^{1}$

Silvia Santiago ${ }^{3}$

Ana Lucia Medeiros de Souza ${ }^{1}$

Sandra Maria Spedo ${ }^{1}$

${ }^{1}$ Departamento de Medicina Preventiva, Escola Paulista de Medicina, Universidade Federal de São Paulo (EPM-Unifesp). R.

Botucatu 740, Vila Clementino. 04023-062

São Paulo SP.

luizcecilio60@gmail.com

${ }^{2}$ Instituto Superior de

Ciências do Trabalho e da

Empresa, Instituto

Universitário de Lisboa

(Iscte-IUL).

${ }^{3}$ Departamento de Saúde

Coletiva, Faculdade de

Ciências Médicas,

Universidade Estadual de

Campinas (Unicamp).

\begin{abstract}
The enhancement of primary healthcare has been a core strategy for the empowerment of the Brazilian Unified Health System (SUS). Recent guidelines issued by OPAS and the Ministry of Health highlight the role it has played as a thematic communication network center, a regulating agent for the access and use of services required for comprehensive healthcare. Sponsored by PPSUS/Fapesp, this study examines the possibilities of the primary healthcare network exercising such a strategic function. Life narratives involving 15 regular users were produced in two cities of ABC Paulista, which have adopted the Family Health Strategy for the organization of their primary healthcare networks. The study presents three main findings: the primary healthcare network serves as an outpost of SUS by producing user values even for high complexity service users; the primary network is perceived is a place for simple care needs; there is shared impotence between users and teams when it comes to the network functioning as the coordinator of care, indicating that it does not possess the technological, operational and organizational material conditions or symbolic conditions (values, meanings, and representations) to be in a central position in the coordination of thematic healthcare networks.
\end{abstract}

Key words Primary healthcare, Access, Thematic healthcare networks, Coordination of care
Resumo O fortalecimento da atenção básica tem sido valorizado como estratégia central para a construção do SUS. Diretrizes recentes emanadas pela OPAS e pelo MS destacam seu papel como centro de comunicação de redes temáticas, como reguladora do acesso e utilização dos serviços necessários para a integralidade do cuidado. O presente estudo, financiado com recursos PPSUS/Fapesp, problematiza as possibilidades da rede básica exercer tal função estratégica. Foram produzidas narrativas de vida de 15 usuários altamente utilizadores de serviços de saúde em dois municípios do ABC paulista, que adotaram a Estratégia de Saúde da Família para organização de suas redes básicas. O estudo apresenta três achados principais: a rede básica funciona como posto avançado do SUS, produzindo valores de uso mesmo para os pacientes utilizadores de serviços de alta complexidade; a rede básica é vista como lugar de coisas simples; há uma impotência compartilhada entre usuários e equipes quando se trata da rede básica funcionar como coordenadora do cuidado, indicando como ela não reúne condições materiais (tecnológicas, operacionais, organizacionais) e simbólicas (valores, significados e representações) de deter a posição central da coordenação das redes temáticas de saúde.

Palavras-chave Atenção primária à saúde, Acesso, Redes temáticas em saúde, Coordenação do cuidado 
[...] Contar significa reconhecer um pesadelo, mas também lhe dar um fim.

Era ao mesmo tempo a dor e o remédio. O que ela escondia era também o que revelava $[\ldots]$ Bernardo Carvalho ${ }^{1}$

\section{Introdução}

A Atenção Primária à Saúde (APS), ou a Atenção Básica em Saúde $(\mathrm{ABS})^{2}$, como tem sido preferencial, mas não exclusivamente denominada no Brasil, e que será utilizada neste artigo, vem ocupando, desde a sua enunciação como uma política para a reorganização da atenção à saúde pela Organização Mundial da Saúde $(\mathrm{OMS})^{3}$ na década de 70, um estatuto estratégico de intervenção e de formulação teórica para os Sistemas Nacionais de Serviços de Saúde (SNSS). Se, num primeiro momento, foi pensada para sociedades com níveis de desenvolvimento menos elevados, hoje ela é assumida como o principal dispositivo de organização, constituição e articulação das redes de atenção à saúde para muitos países ditos centrais ${ }^{4,5}$.

Quando se trata do acesso da população aos serviços de saúde, a ABS tem sido pensada, tanto como a porta de entrada do sistema, como o primeiro nivel de contato da população com o sistema, aquele mais próximo às famílias e à comunidade. Para Starfield ${ }^{6}$, é a ABS que deve coordenar os fluxos dos usuários entre os vários serviços de saúde, buscando garantir maior equidade ao acesso e à efetiva utilização das demais tecnologias e serviços do sistema, para responder às necessidades de saúde da população.

No Brasil, foi com o movimento da reforma sanitária, que desembocou na criação do Sistema Único de Saúde (SUS), em particular a partir do final dos anos 1980, quando os municípios assumiram progressivamente a prestação de cuidados básicos para seus cidadãos, que as ações de atenção realizadas e ofertadas por estas unidades, progressivamente denominadas de unidades básicas de saúde (UBS), ganharam complexidade, pela ampliação do atendimento médico nas três grandes especialidades (clínica, pediatria e ginecologia), mantidas todas as outras atividades de saúde pública. É um período em que vários desenhos de atenção básica são experimentados, distinguindo-se entre si pelo maior ou menor desenvolvimento do atendimento médico não agendado, pelo grau de incorporação da atenção odontológica e de outros profissio- nais de saúde, pelos modos de se trabalhar o território e a organização do processo de trabalho, em particular pelo grau de adoção ou não de atividades ditas programáticas. As propostas de acolhimento, os conceitos de vínculo e de responsabilidade sanitária também vão ganhando espaço, como pode ser visto nas formulações da política de humanização preconizada pelo SUS7 .

A despeito desta multiplicidade de modelagens da ABS, em 1994, o Ministério da Saúde assume a Estratégia da Saúde da Família (ESF) como a estratégia de atenção à saúde estruturante do SUS.

Em 2006, a Política Nacional de Atenção Básica $^{1}$ ampliou os seus objetivos e reafirmou a ESF como estratégia prioritária e modelo substitutivo para a organização da atenção básica. Dados de 2009, do Ministério da Saúde, indicam que 94\% dos municípios do Brasil dispunham da ESF na sua rede de UBS, responsáveis pelos cuidados de saúde primários, com cobertura de $51 \%$ da população brasileira ${ }^{8}$.

Passados 30 anos do lançamento dos fundamentos da APS, período em que os processos de adoecimento e as necessidades de saúde se transformaram intensamente, vemos seus princípios serem relançados e as suas capacidades de alcance ampliados ${ }^{1}$. No documento apresentado pela OMS, em 2008, com o sugestivo nome Cuidados de saúde primários: agora mais do nunca ${ }^{4}$, ela é novamente apontada como a principal estratégia de reorganização dos SNSS frente às novas demandas colocadas para a saúde. Agora a APS é pensada como ordenadora, coordenadora ou gestora do cuidado de saúde, a partir não mais da diretriz da hierarquização dos serviços, mas pela posição de centralidade que lhe é conferida na constituição de redes de cuidado.

A proposta de que a coordenação das redes de atenção à saúde seja feita a partir da rede básica parte do diagnóstico da falência dos SNSS caracterizada pela descontinuidade dos cuidados, a fragmentação da atenção à saúde e a ainda estratégica posição ocupada pelo hospital na produção dos cuidados'. Há um reconhecimento de que, apesar de todos os esforços, a promessa colocada na ABS de alcançar uma configuração mais racional, integrada e equitativa dos sistemas se saúde, funcionando sempre como sua porta de entrada, ou, pelo menos, porta preferencial para o conjunto dos serviços de saúde, parece nunca se ter plenamente alcançado.

Para Mendes ${ }^{10}$, tendo em vista a crise nos SNSS contemporâneos, é possível perceber em vários países uma reconfiguração das dinâmicas da ABS. 
Três aspectos parecem ser consensualmente identificados nela: a intensificação dos processos de gestão da clínica, a constituição de redes de cuidado e a contratualização das equipes da ABS por metas de produtividade, entre outras iniciativas ${ }^{11-13}$.

Estudos teóricos e empíricos demonstram uma importante distância entre a idealidade dos modelos de atenção à saúde vigentes e as práticas sociais concretas realizadas por usuários e profissionais nos espaços reais de produção de cuidado $^{14,15}$. As indicações de Luz ${ }^{16}$ vão no mesmo sentido quando diz que os modelos são geralmente idealizados[...], e buscamos fazê-los acontecer, materializar, [...] por meio de regras ou normas previamente estabelecidas, sendo entretanto estes atos realizados por diferentes trabalhadores, que também agem com seus saberes e experiências, gerando um conjunto diferenciado de práticas, com novas e distintas modelagens.

Uma responsabilização ampliada para a atenção básica tem sido posta na agenda de debate nacional, particularmente a partir da proposta de criação das grandes redes temáticas de cuidado, coordenadas a partir exatamente da rede bási$c a$, que funcionaria como centros de comunicação no interior delas ${ }^{17,18}$. São as reais possibilidades (ou limites ou condicionantes) para o exercício dessa responsabilidade ampliada posta para a ABS que serão objeto de atenção no artigo, examinadas a partir dos achados de uma investigação, em curso, sobre as múltiplas lógicas do acesso e da utilização de serviços ${ }^{19}$.

\section{Percurso metodológico}

Os resultados apresentados aqui fazem parte do projeto As múltiplas lógicas de construção de redes de cuidado no SUS: indo além da regulação governamental do acesso e utilização de serviços de saú$d e^{19}$, em andamento, financiado pela FapespPPSUS. O estudo, de caráter qualitativo, está sendo realizado em dois municípios de grande porte da região do ABCD paulista.

As cidades, apesar de histórias distintas de construção do SUS local, contam hoje com uma rede organizada de atenção básica, de atenção especializada e hospitalar, incluindo serviços de urgência e emergência, além de outros de maior densidade tecnológica de referência regional. Ambos os municípios adotam a ESF como modelo preferencial para organização da atenção básica, com uma cobertura superior a 90\% de Agentes Comunitários de Saúde (ACS). A despeito das diferenças socioeconômicas e demo- gráficas das cidades, seus perfis epidemiológicos são semelhantes.

$\mathrm{Na}$ primeira fase da pesquisa, de caráter exploratório e já concluída, foram realizadas entrevistas temáticas em profundidade com atores políticos estratégicos dos municípios (prefeito, secretário de saúde e conselheiros municipais de saúde) e com profissionais selecionados do SUS municipal (enfermeiro, agente comunitário de saúde e médico) com longa história de inserção no sistema local.

Nesta fase exploratória, chamou atenção a surpreendente regularidade com que os atores entrevistados afirmavam que boa parte dos problemas de atenção à saúde - os prontos-socorros sempre lotados, as longas filas de espera por especialistas, a falta de leitos, o agravamento das complicações por doenças crônicas - deveriam ser resolvidos, ou, pelo menos, minimizados quando a rede básica cumprisse o papel que the é reservado, em particular a responsabilização pela população de sua área de cobertura, a estratificação de riscos e o desenvolvimento de atividades de promoção e prevenção. Uma rede básica que, idealmente, funcionaria como a referência preferencial para os contatos, a entrada e a circulação das pessoas no sistema de saúde, em função da proximidade territorial dos lugares onde elas vivem, portanto como a grande garantia de acesso a um sistema de saúde universal, inclusivo, capaz de garantir os princípios de integralidade e equidade inscritos no texto constitucional. Um novo funcionamento da rede básica requerido como elemento central para uma adequada regulação do acesso aos serviços de saúde nos municípios.

Tais expectativas dos atores estratégicos foram agrupadas em uma categoria empírica denominada "a quimera da rede básica". Quimera entendida como o sonho que nunca se realiza plenamente. Todos os atores reconheciam que, apesar de tantos investimentos, a rede básica não cumpria as expectativas que lhe eram depositadas. Esta categoria foi retomada na segunda fase do estudo, tentando, agora, compreendê-la melhor pela incorporação da experiência dos usuários na utilização dos serviços básicos de saúde.

Para a segunda fase do estudo adotou-se o método biográfico ${ }^{20}$, com a coleta das histórias de vida de usuários dos serviços de saúde. A abordagem biográfica ${ }^{21,22}$, como preferem denominar alguns autores, tem sido empregada cada vez mais frequentemente pelas ciências sociais e humanas.

Para Houle ${ }^{22}$, as histórias de vida são o resultado da elaboração de uma experiência ou de expe- 
riências de vida [....] e, por mais singulares que elas sejam, podem ser consideradas como experiências "da vida em sociedade”. Na saúde, o emprego da abordagem biográfica é mais recente. No nosso meio destacam-se os trabalhos realizados por Schraiber ${ }^{23}$ que, utilizando-se das histórias de vida de médicos graduados nas primeiras décadas do século passado, reconstrói a transição da medicina liberal para a medicina tecnológica $^{23,24}$. A abordagem biográfica também foi utilizada por Carapinheiro ${ }^{14}$ e Andreazza ${ }^{15}$ para, a partir da coleta das experiências de usuários pelos percursos labirínticos e desordenados do sistema de saúde, reconstituirem os recursos que as pessoas se utilizam para traçar os caminhos mais rápidos e eficazes para resolver seus problemas de saúde, construir suas redes preferenciais de acesso, suas tramas de contorno de obstáculos e os sentidos atribuídos aos distintos processos de produção de cuidado.

O estatuto do usuário nesta investigação não é do mero entrevistado, pois não se trata aqui de uma pesquisa de opinião ou de satisfação dos doentes sobre a $\mathrm{ABS}^{25}$. Assumimos, como propõem Ceccim e Merhy ${ }^{26}$, que o saber que os usuários adquirem na utilização concreta dos serviços básicos de saúde poderá ocupar um caráter assessor no constante processo de busca de aperfeiçoamento da ABS.

$\mathrm{Na}$ segunda fase do estudo, entrevistaram-se 15 usuários com o objetivo de se reconstituir, a partir das suas experiências diante de um ou mais processos de adoecimentos, como é feito o acesso e a utilização dos serviços de saúde. Eles foram indicados por agentes comunitários de saúde dos municípios estudados, tendo como critério serem pessoas grandes utilizadoras dos serviços de saúde.

No Quadro 1, estão descritas as principais características das pessoas entrevistadas. Todas elas foram agendadas por telefone pelos próprios investigadores e realizadas no domicílio dos usuários, gravadas em meio digital, com a anuência do entrevistado, que assinava os Termos de Consentimento Livre e Esclarecido, conforme aprovação do Comitê em Ética em Pesquisa da Unifesp, e posteriormente transcritas.

Referências à atenção básica feitas pelos entrevistados, seja de modo espontâneo, seja provocadas pelos entrevistadores, foram recortadas e submetidas à análise do tipo temática e agrupadas em três categorias empíricas: a rede básica como posto avançado do SUS; a rede básica como lugar das coisas simples; a rede básica como espaço da impotência compartilhada entre equipes e usuários. Estas três categorias, quando lidas em conjunto, resultam em indicações empíricas que nos possibilitam ter um pouco mais claro o lugar que a rede básica ocupa na atual configuração do sistema de saúde, tendo em vista a perspectiva de seus usuários.

\section{Resultados e discussão}

\section{A rede básica como posto avançado do SUS}

Esse Posto aqui é uma benção pra nós (P15)

Foram agrupadas nessa primeira categoria todas as referências positivas ao atendimento recebido na rede básica, em particular como ela é vista como produtora de valores de uso pelos entrevistados. Por sua crescente capilarização e pela consequente maior proximidade física e acessibilidade para os usuários, a rede básica é percebida como um posto avançado da política pública que é o SUS.

O cuidado prestado aos diabéticos é bem avaliado nos dois municípios estudados, valorizado por ser um tratamento completo, pois fornece insulina além do aparelho para medir a glicemia.

Olha, eu acho que eu continuaria na UBS [se voltasse a ter um plano de saúde], principalmente, por causa do problema da diabetes. Porque eu tenho uma ajuda muito grande sobre o problema da diabetes. Então, eu não desprezaria a UBS não. A insulina, o aparelhinho pra fazer o destro [...] (P2).

Há o reconhecimento, também, na maior agilidade para realização de exames.

Aqui no Posto mesmo. Porque aqui mesmo você pega o pedido, você faz. Demora, geralmente, 15 a 20 dias já chega o resultado. [...] Está mais fácil [do que] há um ano e meio atrás, 2 anos atrás [...]. Porque agora tá mais rápido, antigamente, demorava pra vir o resultado $(\mathrm{P} 4)$.

Temos, ainda, a oportunidade de observar como no cotidiano das unidades, na sua micropolítica, ocorrem momentos de cuidado e vínculo, que nem sempre são visíveis para os gestores, mas que são reconhecidos e valorizados pelos usuários, em particular como, em várias situações, os profissionais identificam e respondem à necessidade de flexibilização do acesso para atender alguma situação mais aguda. Flexibilização orientada mais pela necessidade do usuário naquele momento, do que por determinadas regras estabelecidas para o funcionamento do serviço, ou seja, mais vinculado à ética profissional, do que às normas e regras que pautam a racionalidade formal da organização. 
Quadro 1. Características das pessoas estudadas.

\begin{tabular}{|c|c|c|c|c|c|}
\hline Pessoa & Sexo & $\begin{array}{l}\text { Idade } \\
\text { (anos) }\end{array}$ & Situação familiar & Situação de trabalho & $\begin{array}{c}\text { Principais problemas } \\
\text { de saúde }\end{array}$ \\
\hline $\mathrm{P} 1$ & Fem. & 44 & $\begin{array}{l}\text { Casada, } 3 \text { filhos, moram todos } \\
\text { juntos. }\end{array}$ & Aposentada, foi ACS & $\begin{array}{l}\text { Depressão pós-parto e } \\
\text { síndrome do pânico }\end{array}$ \\
\hline P2 & Fem. & 47 & Casada, 1 filho e uma neta. & & $\begin{array}{l}\text { DM, cardiopatia e } \\
\text { hemorragias-anemia. }\end{array}$ \\
\hline P3 & Masc. & 64 & $\begin{array}{l}\text { Casado, } 3 \text { filhas, uma já } \\
\text { falecida }\end{array}$ & $\begin{array}{l}\text { Aposentado. Foi } \\
\text { operário da indústria } \\
\text { automobilística. }\end{array}$ & $\begin{array}{l}\text { HAS, DM e } \\
\text { Cardiopatia }\end{array}$ \\
\hline $\mathrm{P} 4$ & Fem. & 35 & $\begin{array}{l}\text { Casada, } 3 \text { filhos. Moram todos } \\
\text { juntos. }\end{array}$ & $\begin{array}{l}\text { Do lar. Trabalhou com } \\
\text { transporte }\end{array}$ & $\begin{array}{l}\text { Hipoglicemia e dor de } \\
\text { cabeça. }\end{array}$ \\
\hline P5 & Fem. & 72 & $\begin{array}{l}\text { Casada/separada, } 3 \text { filhos, mora } \\
\text { com o marido duas filhas, o } \\
\text { genro e uma neta. }\end{array}$ & $\begin{array}{l}\text { Aposentada. Trabalhou } \\
\text { com serviços } \\
\text { domésticos }\end{array}$ & $\begin{array}{l}\text { Artrose, asma, hérnia, } \\
\text { HAS, DM e } \\
\text { dificuldades auditivas }\end{array}$ \\
\hline P6 & Fem. & 39 & $\begin{array}{l}\text { Casada, } 7 \text { filhos. Moram todos } \\
\text { juntos. }\end{array}$ & $\begin{array}{l}\text { Do lar. Vendia bala no } \\
\text { sinal. }\end{array}$ & $\begin{array}{l}\text { Filho especial: sequelas } \\
\text { neurológicas e motoras } \\
\text { por meningite. }\end{array}$ \\
\hline P7 & Masc. & 57 & $\begin{array}{l}\text { Casado. } 4 \text { filhos, } 2 \text { netos. } \\
\text { Moram com eles um filha e o } \\
\text { genro. }\end{array}$ & $\begin{array}{l}\text { Aposentado. Foi } \\
\text { operário da indústria } \\
\text { automobilística. }\end{array}$ & $\begin{array}{l}\text { Acidente de trabalho, } \\
\text { hérnia de disco, } \\
\text { alcoolismo, HAS }\end{array}$ \\
\hline P 8 & Masc. & & $\begin{array}{l}\text { Casado, } 1 \text { filha. Mora com a } \\
\text { esposa }\end{array}$ & $\begin{array}{l}\text { Aposentado. Foi } \\
\text { operário da indústria } \\
\text { automobilística. }\end{array}$ & $\begin{array}{l}\text { Acidente de trabalho- } \\
\text { lesão na coluna e grave } \\
\text { lesão na mão. }\end{array}$ \\
\hline P9 & Fem. & 52 & $\begin{array}{l}\text { Casada, } 4 \text { filhos, } 8 \text { netos. Mora } \\
\text { com o marido e o filho caçula. }\end{array}$ & $\begin{array}{l}\text { Diarista. Está sem } \\
\text { trabalhar há três meses. }\end{array}$ & $\begin{array}{l}\text { Artrite reumatóide, } \\
\text { HAS e DM }\end{array}$ \\
\hline P10 & Fem. & 57 & $\begin{array}{l}\text { Casada, } 2 \text { filhos que vivem com } \\
\text { ela, além também de uma neta } \\
\text { e a mãe }\end{array}$ & Do lar. & $\begin{array}{l}\text { Obesidade mórbida } \\
\text { com dificuldade de } \\
\text { locomoção }\end{array}$ \\
\hline P11 & Masc. & 73 & $\begin{array}{l}\text { Casado, } 6 \text { filhos. Mora com a } \\
\text { esposa. }\end{array}$ & $\begin{array}{l}\text { Aposentado. Foi } \\
\text { Metalúrgico. }\end{array}$ & $\begin{array}{l}\text { HAS, DPOC e cardíaco } \\
\text { (cirurgia para colocação } \\
\text { de marcapasso) }\end{array}$ \\
\hline P12 & Masc. & 54 & $\begin{array}{l}\text { Casado, } 2 \text { filhos, vive com a } \\
\text { esposa e um filho }\end{array}$ & $\begin{array}{l}\text { Aposentado. Foi } \\
\text { metalúrgico. }\end{array}$ & HAS, ICC e catarata \\
\hline P13 & Fem. & 70 & $\begin{array}{l}\text { Viúva, uma filha e } 3 \text { netos. } \\
\text { Mora sozinha, em casa } \\
\text { contigua da irmã. }\end{array}$ & $\begin{array}{l}\text { Aposentada, foi } \\
\text { faxineira e artesã } \\
\text { (comercializava em casa). }\end{array}$ & $\begin{array}{l}\text { HAS, DM e } \\
\text { Cardiopata }\end{array}$ \\
\hline P14 & Fem. & 70 & $\begin{array}{l}\text { Solteira, } 2 \text { filhos. Mora com o } \\
\text { filho, a filha, o genro e dois } \\
\text { netos }\end{array}$ & $\begin{array}{l}\text { Aposentada, serviços } \\
\text { gerais de limpeza. }\end{array}$ & $\begin{array}{l}\text { Atualmente, câncer de } \\
\text { mama }\end{array}$ \\
\hline P15 & Fem. & 52 & $\begin{array}{l}\text { Viúva, um filho. Mora com a } \\
\text { mãe e com o filho }\end{array}$ & $\begin{array}{l}\text { Aposentada, foi } \\
\text { costureira e babá. }\end{array}$ & $\begin{array}{l}\text { HAS, problemas renais } \\
\text { e transplante de Rim }\end{array}$ \\
\hline
\end{tabular}


São muitas as indicações que permitem afirmar que a rede básica produz valores de uso para os usuários nos dois municípios, mesmo que não seja exatamente o que as várias formulações de modelos assistenciais definem que ela deva produ$z i r$. E não é de pouca importância o que a $A B S$ consegue oferecer. Vale a pena lembrar que o estudo está utilizando biografias de pacientes que vivem situações bastante graves de saúde, e que são utilizadores dos serviços de maior densidade tecnológica. Portanto, a complexidade dos casos estudados, que poderia ser considerada um viés para a avaliação da ABS, mostrou de modo surpreendente como, mesmo para esses pacientes, ela é reconhecida e funciona como referência e elemento importante para a composição do cuidado de que necessitam. Dos quinze pacientes entrevistados, nove fizeram referência explicitamente positiva de utilização da rede básica ou reconheceram que encontram respostas para suas necessidades nela. É claro que aqui não há nenhuma pretensão quantitativa de análise, numa métrica linear que avalia a importância pelo volume das referências, mas, reconhece-se, que há situações em que a quantidade é um indicativo de qualidade.

Os entrevistados são pessoas que se utilizam de serviços mais complexos que, frequentemente os "sequestram", produzindo circuitos próprios de circulação e gestão do cuidado. Portanto, o reconhecimento dos valores de uso produzidos pela ABS por esses pacientes é altamente indicativo do quanto a rede básica constitui-se, de fato, em posto avançado do SUS para as pessoas, lugar para obtenção de recursos que irão utilizar na composição de sua cesta de cuidados, que, como sabemos, deverá ser completada com recursos existentes em outros pontos do sistema.

\section{A rede básica como lugar das coisas simples}

[Na UBS] É mais pra buscar remédio, medir a pressão, e essas coisinhas aí. De vez em quando eu passo com o médico. Mas não é sempre não (P13).

O primário, assim, ver uma pressão alta, uma febre de uma criança, uma gripe, uma coisa, é super bem atendido. A dificuldade toda é você conseguir marcar com um especialista [...] (P1).

$\mathrm{O}$ fornecimento de medicamentos, seja pela dispensação direta na farmácia, seja para obtenção de receita do médico, parece ser o valor de uso mais imediatamente visível da rede básica para os usuários. $\mathrm{O}$ acesso aos medicamentos funcionaria como um "chamariz" para levar os pacientes às UBS. Como vimos na primeira categoria, a rede básica produz mais valores de uso para além dos medicamentos, mas sem dúvida a dependência em relação à eles e, também, a busca pelo fornecimento de guias para acesso aos serviços de maior complexidade é que "obrigam" os usuários a incluírem a rede básica nos seus cálculos ou em suas estratégias para conseguir o cuidado de que precisam. Mesmo assim, e tentando caracterizar o enunciado desta segunda categoria empírica, há uma percepção de que a farmácia da UBS oferece os medicamentos mais baratos. Vale notar aqui que, embora eles sejam elementos importantes para a ida dos usuários às unidades, pois sua obtenção gratuita provavelmente desonera o orçamento familiar, chama a atenção como eles são vistos como mais baratos, uma primeira indicação de como eles identificam a rede básica como o lugar das coisas mais simples.

Porque só vem pra aqui remédio que é baratinho, e aí, eu tenho que comprar [os mais caros] (P15).

Para além da obtenção de medicamentos, a rede básica é vista como passagem obrigatória para a obtenção de "guias" (encaminhamentos), pedidos de exames e mesmo de documentos para se conseguir os benefícios sociais.

Uma percepção bastante compartilhada entre os entrevistados, e que reforça o sentido da atenção básica como o lugar de coisas simples, é de que o médico generalista seria um médico com pouca resolutividade, em particular como um encaminhador para o especialista e como um "trocador de receitas" vindos do especialista, tal qual expressa o relato abaixo:

Mas aí, não é bem passar [no que o paciente considera uma consulta de "verdade", quando está doente]. Mas eu já tenho consulta agendada, sempre a gente passa com ele a cada 3 meses. Que é pra renovar um remédio aí, de pressão alta, e de diabete ( $\mathrm{P9})$.

A combinação do seguimento com algum especialista, em um serviço de referência, com o seguimento pelo médico generalista da UBS é bastante frequente. Em geral, as coisas mais "simples" como hipertensão arterial e diabetes são seguidas na própria unidade e o problema mais "grave" é acompanhado pelo especialista. Apesar de se poder afirmar que existe uma complementaridade da ação dos dois tipos de profissionais, parece haver sempre a dúvida se a competência clínica do generalista funciona de forma supletiva, substitutiva ou sobreposta à competência clínica do especialista, ou se, apenas, se limita a ser um "sinalizador de percursos" e um "trocador de receitas". 
De qualquer forma, fica evidente como os usuários combinam ativamente os cuidados do especialista com as consultas do generalista. $\mathrm{O}$ médico generalista da UBS trabalha em parceria "informal e subalterna" com o especialista que detém sempre a última palavra sobre o tratamento mais adequado. O polo especializado é dominante em relação ao da rede básica, até porque nos casos estudados não se percebe uma "disputa" do generalista para tomar para si a condução do cuidado. Para os usuários ele parece $a b d i$ car da autoridade para assumir a efetiva coordenação do seu cuidado.

[...] ele [o médico do PSF] fala: 'Olha, dona [....], isso [o diabetes] é uma coisa que tem que fazer com um especialista.' [...] Aí o Dr. I. [médico da ESF] só renova, né? [...] Ele só renova com o mesmo [remédio] que o médico do [hospital] passou quando eu tava internada... Que é o remédio da diabete (P9).

Este abrir mão da condução do cuidado pelo generalista merece uma discussão mais aprofundada. Ela poderia ser fruto do modo como os médicos encaram ou entendem suas responsabilidades ou possibilidades de atuação na rede básica, consequência do que poderíamos designar como ideologia assistencial-preventivista presente no conceito de "atenção primária", que pensaria a ESF mais como lugar de ações preventivas do que "curativas".

A competência do generalista para cuidar tanto de crianças, como de mulheres e de adultos chega a ser abertamente questionada por uma entrevistada ao afirmar que:

[A médica da ESF] [...] É, ela é tudo, é pediatra, é ginecologista, é clínica geral, é obstetra. [...] Ela é de tudo pra mim também. [...] Então, eu acredito na minha cabeça que um médico não estuda pra tudo isso. Ele não faz uma faculdade de ginecologista, outra de clínico geral. Outra de pediatra, eu acredito que não. [...] Então, pra mim, eu acho isso (P4).

Outra característica das UBS é como os usuários percebem sua incapacidade e descompromisso de atendimento em casos de urgência, o que resulta na percepção de que em situações de urgência nem vale a pena "perder tempo" indo à UBS, melhor sendo procurar os serviços de urgência como primeira opção.

Como diz uma paciente questionada para onde ela levava o filho que tem necessidades especiais ao apresentar algum problema de saúde

[...] Porque de repente o meu filho dá uma febre, eu não vou ligar pro Posto: Ah, meu filho, vem aqui! Eu não, fia, eu meto ele dentro do ônibus, e eu vou que vou! [...] Em qualquer hospital, minha filha! (P6)

$\mathrm{Ou}$, como diz outra paciente:

No Pronto Socorro mesmo [onde vai quando precisa de atendimento por algum problema de saúde], porque na UBS a gente vai e é difícil ter um médico, assim, disponível. Porque você chega lá, se você tiver passando mal, você tem que esperar vaga e voltar. [...]. Porque pra aqui não adianta vir, porque você passa raiva ( $\mathrm{P} 4)$.

Por tudo isso é possível dizer que, apesar dos usuários reconhecerem valores de uso nas UBS e buscarem nelas recursos que julgam importantes para a composição do seu cuidado, parecem perceber claramente o que podem e o que não podem esperar dela: conseguem medicamentos de modo gratuito, mas são baratinhos; conseguem consulta médica, mas com um generalista que atua como o polo subordinado em relação ao especialista; conseguem atendimento mediante agendamento, mas sabem que não podem contar efetivamente com a equipe em situações que avaliam como tendo necessidade de atendimento urgente. É isso que nos permite afirmar que os usuários dão o significado da ABS como lugar das coisas simples. A rede básica no seu caráter de complementaridade, mas também de subalternidade em relação aos serviços de saúde e profissionais que operam com maior complexidade tecnológica.

\section{A rede básica como espaço da impotência compartilhada entre equipes e usuários}

Porque na UBS não adianta você falar, porque eles alegam que já não podem fazer mais nada, o que eles podiam fazer, já fez (P2).

As histórias só confirmam o quanto o acesso à média e a alta complexidade é a grande dificuldade vivida pelos usuários, e, ao mesmo tempo, o seu objeto de desejo. Os prazos de espera relatados são terríveis. Há um desconhecimento dos rumos das coisas. Há uma zona cinzenta de incerteza e de imponderabilidade que parece impenetrável para a equipe e os pacientes. O que chama a atenção nas narrativas é o quanto os usuários compartilham de sua impotência com os profissionais da UBS, em particular com o médico. A equipe lhes parece sempre tão desinformada, tão impotente quanto eles. Uma impotência compartilhada!

Então, eles, o pessoal da UBS aqui, não tem muita culpa, porque a culpa eu não sei de onde vem (P15).

[...] E elas falam: Gente, o que a gente pode fazer, é aguardar. Se a gente pudesse fazer alguma 
coisa a mais, a gente tinha feito, mas a gente depende dos outros (P2).

Como o processo de encaminhamento via regulação governamental nunca é claro, parece sempre haver um elemento "sorte" no acesso aos serviços, tal como nos relata o paciente:

Tipo assim: Eles mandam a nossa guia pra Central de Vagas. Aí depende da sua sorte, ou vai pro [ambulatório de especialidades Municipais], ou vai pro [dois hospitais de referências da região], entendeu? Aí depende, e a minha tinha saído pro [Hospital 1 de referência] (P10).

Merece atenção o fato de que os recortes da atenção básica trouxeram um plus não esperado: muito se falou da média e alta complexidade. Ou seja, as referências à rede básica sempre vieram "contaminadas" pela experiência frustrada do acesso à média complexidade. Os entrevistados nunca falam da atenção básica sem fazer sua imediata conexão com os demais serviços, daí a frustração decorrente da percepção da impotência ou da não governabilidade da equipe da UBS para produzir uma efetiva articulação com os outros níveis do sistema de saúde. O usuário identifica, na rede básica, profissionais que não podem efetivamente fazer muita coisa para garantir o que mais deseja: o consumo das tecnologias, em tempo adequado, que julga necessárias para se sentir bem cuidado. Assim, a UBS serve como observatório das dificuldades de acesso aos serviços de média e alta complexidade, nem sempre conseguindo ser o ponto de apoio quando se trata de alcançar outros níveis do sistema de saúde, o que se torna central para uma compreensão do lugar que ela efetivamente possa ocupar como centro de comunicação ou coordenadora da rede de atenção à saúde, tal qual enunciado pelo Ministério da Saúde ${ }^{17,18,27}$.

Por mais que julguemos que tais necessidades possam ser "distorcidas", uma simples reprodução ideológica de "falsas necessidades" que a medicina tecnológica em parceria com o complexo médico-industrial vai produzindo sem cessar, o fato é que aquele usuário real, movendo-se na ordem de significados que vai sendo socialmente produzida, almeja conseguir tal consumo. E é partir de tal julgamento que vai produzindo significados para a rede básica real, muito além de todos os modelos idealizados do seu funcionamento.

\section{Considerações finais}

Para responder à questão que compõe o título do artigo, qual seja, qual pode ser o papel da rede básica na construção das redes temáticas, duas ordens de questões devem ser consideradas. A primeira, é que a ABS tornou-se um posto avançado do SUS, lugar onde as pessoas buscam recursos fundamentais para compor o cuidado de que precisam. A vida dos brasileiros seria mais difícil sem ela. A rede básica é uma produtora de valores de uso para milhões de cidadãos. Nesse sentido, ela deve ser defendida como uma conquista a ser consolidada e aperfeiçoada. A segunda questão é que a ABS, por um conjunto de razões que se apóiam em evidências colhidas na pesquisa cujos resultados preliminares alimentam este artigo, não reúne condições materiais e simbólicas para funcionar como o centro de comunicação entre os vários pontos que compõem as complexas redes de cuidado, nesse momento em que o Ministério da Saúde ${ }^{9,17,18,27}$ coloca na ordem do dia a construção das redes temáticas.

Há o risco de ficarmos, discursivamente, reiterando tal papel para a atenção básica quando, na prática, e para as pessoas vivendo situações de grandes carências e vulnerabilidade, os arranjos para a responsabilização e gestão do cuidado deverão ser muito mais complexos e articulados. $\mathrm{O}$ que fazer então? Pensamos que dois movimentos complementares podem ser feitos no sentido de se avançar na constituição, coordenação e operacionalização das redes temáticas. O primeiro, é que a coordenação das redes assumirá múltiplas configurações a depender dos diferentes contextos locorregionais do SUS. Isso significa que os mais variados arranjos, composições, lócus institucionais de operacionalização deverão ser experimentados, incluindo graus diferentes de participação e responsabilidade da $A B$, sempre na perspectiva da materialização de redes de serviços funcionalmente integradas que propiciem a integralidade do cuidado que as pessoas necessitam.

O segundo movimento vai no sentido de investimentos na $A B S$ para que ela possa, progressivamente, ampliar sua capacidade de intervir ativamente nos processos regulatórios, consolidando gradualmente sua legitimidade perante os usuários como efetivo centro de comunicação com os demais serviços. Acesso direto das equipes locais para marcação de consulta, criação de mecanismos formais e regulares de comunicação entre médicos da rede de atenção básica e as centrais reguladoras e qualificação dos processos microregulatórios nas unidades, são algumas medidas factíveis e que já têm sido experimentadas nos municípios estudados.

No entanto, e para finalizar o artigo, buscamos em Carapinheiro ${ }^{14}$ a reflexão sobre o quan- 
to é falsa a imagem de harmonia entre os cuidados, e quão complexa é a trama urdida pelos indivíduos no uso dos centros de saúde, hospitais, clinicas e consultórios privados, emergindo em cada história uma história única, constituída por percursos impulsionados por movimentos irreprimíveis de ação no sistema e de reação ao sistema. São os usuários, portanto, a partir das suas distintas experiências de encontro ou desencontro com os serviços de saúde, que vão construindo novos agenciamentos para conseguir o acesso à rede de serviços, fazendo usos variados da ABS em função de suas singulares necessidades e as ofertas reais feitas por ela. Cabe-nos escutar esse saber assessor que vai sendo produzido de forma irreprimível pelos usuários, e utilizá-lo para o permanente e necessário aperfeiçoamento das redes de cuidado de saúde.

\section{Colaboradores}

LCO Cecilio é o responsável pela concepção da investigação e do artigo, e trabalhou na metodologia, na análise, interpretação do material empírico e na redação final. $\mathrm{R}$ Andreazza trabalhou na concepção, na metodologia, na coleta do material empírico e na redação final. G Carapinheiro trabalhou na concepção da pesquisa, na metodologia, na análise do material empírico e na revisão crítica do artigo. EC Araújo e LA Oliveira trabalharam na coleta, na organização, na sistematização e na análise do material empírico. MGG Andrade, CS Meneses, NRS Pinto, DO Reis, S Santiago, ALM Souza, SM Spedo, trabalharam na coleta e na análise do material empírico.

\section{Agradecimentos}

Nossos agradecimentos aos representantes dos gestores dos municípios estudados, Flavius Augusto Olivetti Albieri e Larissa Desiderá Santo André e aos colegas Florianita C.B. Campos, Claudia Regina Magnabosco-Martins, Sonia Maria de Melo e Tarcísio de Oliveira Braz que têm participado ativamente desta investigação e do grupo de pesquisa de Política e Gestão em Saúde. Por fim, agradecemos especialmente os Agentes Comunitários em Saúde, que indicaram os usuários, e as elas e eles que se dispuseram nos contar suas histórias de vida. 


\section{Referências}

1. Bernardo C. O Sol se põe em São Paulo. São Paulo: Companhia das Letras; 2007.

2. Brasil. Ministério da Saúde (MS). Secretaria de Atenção à Saúde. Departamento de Atenção Básica. Política Nacional de Atenção Básica. Brasília: DAB/SAS/ MS; 2006.

3. Organização Mundial da Saúde. Cuidados primários de saúde: Relatório da Conferência Internacional sobre cuidados primários de saúde; 1978. [site na Internet]. [acessado 2012 set 28]. Disponível em: http:// www.saudepublica.web.pt/05-PromocaoSaude/ Dec_Alma-Ata.htm\#Alma

4. Organização Mundial de Saúde (OMS). Relatório Mundial da Saúde 2008. Cuidados de Saúde Primários: agora mais que nunca. Lisboa: Ministério da Saúde; 2008.

5. Conill EM. Ensaio histórico-conceitual sobre a Atenção Primária à Saúde: desafios para a organização de serviços básicos e da Estratégia Saúde da Família em centros urbanos no Brasil. Cad Saude Publica 2008; 24(Supl. 1):S7-S275.

6. Starfield B. Atenção Primária: equilíbrio entre necessidades de saúde, serviços e tecnologia. Brasília: Unesco, Ministério da Saúde; 2002

7. Brasil. Ministério da Saúde (MS). Secretaria de Atenção à Saúde. Política Nacional de Humanização. Cadernos HumanizaSUS. Ministério da Saúde, Secretaria de Atenção à Saúde, Política Nacional de Humanização. Brasília: MS; 2010.

8. Brasil. Atenção Básica da Saúde da Família: resultados alcançados em 2009. Portal da Saúde. [site na Internet]. [acessado 2012 set 28]. Disponível em :http://dab.saude.gov.br/abnumeros.php.

9. Organização Pan-Americana da Saúde (OPAS). A atenção à saúde coordenada pela APS: construindo as redes de atenção no SUS: contribuições para o debate. Brasília: OPAS; 2011.

10. Mendes EV As redes de atenção à saúde. Cien Saude Colet 2010; 15(5):2297-2305.

11. Teixeira L. Reforma do Centro de Saúde: percursos e discursos. Lisboa: Mundos Sociais; No prelo 2012.

12. Gabe J, Calnan M. The restratification of primary care in England. In: Gabe J, Calnan M, editors. The new sociology of the health service. Abingdon: Routledge; 2009.

13. Pisco L. Reforma da Atenção Primária em Portugal em duplo movimento: unidades assistenciais autónomas de saúde familiar e gestão em agrupamentos de Centros de Saúde. Cien Saude Colet 2011; 16(6): 2841-2852.

14. Carapinheiro G. Inventar percursos, reinventar realidades: doentes, trajectórias sociais e realidades formais. Etnográfica 2001; 2:335-358.

15. Andreazza R, Carapinheiro G, Teixeira L, Cecilio LCO. Do Centro de Saúde à Unidade de Saúde Familiar: narrativas de ausência e intermitências. Anais do $12^{\circ}$. Congresso Paulista de Saúde Pública. Rev Saude Soc 2011; 20(Supl. 1):200-201.

16. Luz MT. Natural, racional, social: razão médica e racionalidade científica moderna. 2a Edição. São Paulo: Hucitec; 2004.
17. Brasil. Portaria 4. 279 de 30 de dezembro de 2010. Gabinete do Ministro. Ministério da Saúde. Estabelece diretrizes para a organização da Rede de Atenção à Saúde no âmbito do Sistema Único de Saúde (SUS). Diário Oficial da União 2010; $31 \mathrm{dez}$.

18. Brasil. Portaria 1.473, de 24 de junho de 2011. Gabinete do Ministro. Ministério da Saúde. Institui os Comitês Gestores, Grupos Executivos, Grupos Transversais e os Comitês de Mobilização Social e de Especialistas dos compromissos prioritários de governo organizados por meio de Redes Temáticas de Atenção à Saúde. Diário Oficial da União 2011; 27 jun.

19. Cecilio LCO, Carapinheiro G, Andrade MGG, Albieri FAO, Santo André LD. As múltiplas lógicas de construção de redes de cuidado no SUS: indo além da regulação governamental do acesso e utilização de serviços de saúde. Anais do $12^{\circ}$. Congresso Paulista de Saúde Pública. Rev Saude Soc 2011; 20(Supl. 1):79-80.

20. Bertaux D. Narrativas de vida, a pesquisa e seus métodos. São Paulo: Paulus Natal, EDUFRN; 2010.

21. Arfuch L. O espaço biográfico: dilemas da subjetividade contemporânea. Rio de Janeiro: Editora UERJ; 2010.

22. Houle G. A sociologia como ciência da vida: a abordagem biográfica. In: Poupart J, Deslauries JP, Groulx AL, Mayer R, Pires A, organizadores. A pesquisa qualitativa: enfoques epistemológicos e metodológicos. Petrópolis: Editora Vozes; 2008. p. 317-334.

23. Schraiber LB. O médico e o seu trabalho. Limites da liberdade. São Paulo: Hucitec; 1993.

24. Schraiber LB. O médico e suas interações: a crise dos vínculos de confiança. São Paulo: Hucitec; 2008.

25. Meneses C, Cecilio LCO, Andreazza R, Cuginotti AP, Reis, AAC, Araujo EC. Os usuários e a transição tecnológica no setor suplementar: estudo de caso de uma operadora de plano de saúde. Cien Saude Colet [periódico na internet]. 2012 mar [acessado 2012 abr]: [cerca de 08 páginas]. Disponível em: http://www.cienciaesaudecoletiva.com.br/artigos/artigo_int.php?id_artigo $=8560$

26. Ceccim RB, Merhy EE. Um agir micro politico e pedagógico intenso: a humanização entre laços e perspectiva. Interface Comun Saúde Educ. 2009: 13(Supl. 1):551-542.

27. Brasil. Decreto no 7.508, de 28 de junho de 2011. Regulamenta a Lei no 8.080 , de 19 de setembro de 1990, para dispor sobre a organização do Sistema Único de Saúde - SUS, o planejamento da saúde, a assistência à saúde e a articulação interfederativa, e dá outras providências. Diário Oficial da União 2011; 29 jun.

Artigo apresentado em 30/04/2012

Aprovado em 17/07/1012

Versão final apresentada em 30/08/2012 